\title{
A TECNOLOGIA ASSISTIVA NO ENSINO SUPERIOR: REFLEXÕES SOBRE SEU USO PARA ALUNOS OUVINTES E SURDOS
}

\author{
LA TECNOLOGÍA ASISTIVA EN LA ENSEÑANZA SUPERIOR: REFLEXIONES \\ SOBRE SU USO PARA ALUMNOS OVINOS Y SURDOS
}

\begin{abstract}
THE ASSISTIVE TECHNOLOGY IN HIGHER EDUCATION: REFLECTIONS ON ITS USE FOR STUDENTS OUTSIDE AND DEAF
\end{abstract}

\author{
Carine $\mathrm{TOSO}^{1}$ \\ Elisabete CERUTTI ${ }^{2}$ \\ Suzete GRANDI ${ }^{3}$ \\ José Anderson SANTOS CRUZ ${ }^{4}$
}

RESUMO: Sabe-se que as tecnologias assistivas buscam reduzir as limitações físicas, podendo romper barreiras e aproximar a comunicação entre sujeitos surdos e ouvintes. Tendo como preocupação os alunos surdos no ensino superior, este trabalho visa a descrever como a cibercultura pode ser um elemento desencadeador de produção de tecnologias assistivas para os alunos surdos. Este trabalho é de cunho bibliográfico, elaborado mediante leitura sistemática de livros e artigos, ressaltando os pontos abordados pelos autores. Inicialmente, serão apresentadas considerações sobre as tecnologias assistivas presentes na sociedade e suas relações com os sujeitos. Em um segundo momento, os conceitos de cibercultura e ciberespaço serão explicitados na intenção de esclarecê-los para, posteriormente, relacioná-los às tendências e evoluções das tecnologias assistivas no Brasil/mundo. Dentre as tecnologias assistivas existentes, este trabalho prioriza as tecnologias da informação e comunicação voltadas para auxiliar a comunicação entre sujeitos surdos e ouvintes presentes nas instituições de ensino superior. Os resultados descrevem que o acesso às Tecnologias da Informação e Comunicação (TIC) pelas pessoas surdas ou com deficiência é um recurso que desencadeia transformações sociais, além de mudanças na forma como o conhecimento é construído. Conclui-se que os recursos tecnológicos saciam parte das limitações oriundas da deficiência auditiva, minimizando as barreiras na comunicação entre ouvintes e surdos.

PALAVRAS-CHAVES: Cibercultura. Tecnologias assistivas. Surdos e ouvintes. Ensino superior.

${ }^{1}$ Universidade Regional Integrada do Alto Uruguai e das Missões (URI), Frederico Westphalen - RS - Brasil. Mestranda em Educação. Integrante do grupo GPE. E-mail: carinetoso@ hotmail.com

${ }^{2}$ Universidade Regional Integrada do Alto Uruguai e das Missões (URI), Frederico Westphalen - RS - Brasil. Professora do PPG Educação URI. Doutora em Educação pela Pontifícia Universidade Católica do Rio Grande do Sul. Líder do grupo GPET e integrante do grupo GPE. ORCID: <https://orcid.org/0000-0002-3467-5052>. Email: beticerutti@uri.edu.br

${ }^{3}$ Universidade de Caxias do Sul (UCS), Caxias do Sul - RS - Brasil. Coordenadora do Serviço de Reabilitação Física da UCS. Doutora em Educação pela Pontifícia Universidade Católica do Rio Grande do Sul. E-mail: sgrandi@ucs.br

${ }^{4}$ Faculdade Anhanguera de Bauru (ANHANGUERA), Bauru - SP - Brasil. Docente A do departamento de pedagogia. Doutorando no Programa de Pós-graduação em Educação Escolar pela Faculdade de Ciências e Letras de Araraquara. Editor Adjunto de Periódicos da Área de Educação. Assessoria e Consultoria para Periódicos. Bolsista CAPES/DS. ORCID: <https://orcid.org/0000-0001-5223-8078>. E-mail: joseandersonsantoscruz@gmail.com

RPGE- Revista on line de Política e Gestão Educacional, Araraquara, v. 22, n. 3, p. 1065-1080, set./dez., 2018. E-ISSN:1519-9029. 
RESUMEN: Se sabe que las tecnologías asistivas buscan reducir las limitaciones físicas, pudiendo éstas, romper barreras y acercar la comunicación entre sujetos sordos y oyentes. En cuanto a los alumnos sordos en la enseñanza superior, este trabajo pretende describir cómo la cibercultura puede ser un elemento desencadenante de producción de tecnologías asistivas para los alumnos sordos. Este trabajo es de cuño bibliográfico, elaborado mediante lectura sistemática de libros y artículos, resaltando los puntos abordados por los autores. Inicialmente, se presentarán consideraciones sobre las tecnologías asistivas presentes en la sociedad y sus relaciones con los sujetos. En un segundo momento, los conceptos de cibercultura y ciberespacio serán explicitados, con la intención de esclarecerlos para posteriormente relacionarlos con las tendencias y evoluciones de las tecnologías asistivas en Brasil / mundo. Entre las tecnologías asitivas existentes, este trabajo prioriza las tecnologías de la información y comunicación dirigidas a auxiliar la comunión entre sujetos sordos y oyentes presentes en las instituciones de enseñanza superior. Los resultados describen que el acceso a las Tecnologías de la Información y la Comunicación (TIC), por las personas sordas o con discapacidad, son recursos que desencadenan transformaciones sociales, además de cambios en la forma en que se construye el conocimiento. Se concluye que los rechazos tecnológicos sacian parte de las limitaciones oriundas de la deficiencia auditiva, minimizando las barreras en la comunicación entre oyentes y sordos.

PALABRAS CLAVES: Cibercultura. Tecnologías asistivas. Sordos y oyentes. Enseñanza superior.

ABSTRACT: It is known that assistive technologies seek to reduce physical limitations, such as breaking down barriers and bringing communication between deaf and hearing subjects. The aim of this work is to describe how cyberculture can be a triggering factor for the production of assistive technologies for deaf students. This work is of bibliographic character, elaborated through systematic reading of books and articles, highlighting the points addressed by the authors. Initially, we will present considerations about the assistive technologies present in society and their relations with the subjects. In a second moment, the concepts of cyberculture and cyberspace will be explained, with the intention to clarify them and later relate them to trends and evolutions of assistive technologies in Brazil / world. Among the existing assistive technologies, this work prioritizes information and communication technologies aimed at helping communication between deaf individuals and listeners present in higher education institutions. The results describe that access to Information and Communication Technologies (ICT) by deaf or disabled people are resources that trigger social transformations, as well as changes in the way knowledge is constructed. We conclude that technological resources are part of the limitations of hearing impairment, minimizing the barriers in communication between listeners and deaf people.

KEYWORDS: Cyberculture. Assistive technologies. Deaf and hearing. Higher education.

\section{Introdução}

A contemporaneidade é uma contingência histórica caracterizada por grandes mudanças. Algumas marcas desse período estão relacionadas ao desenvolvimento tecnológico, que vem avançando de um modo bastante expressivo, e seus efeitos incidem 
sobre nossas vidas. Considerando o contexto tecnológico como algo imanente e, portanto, pertencente à sociedade, este artigo busca analisar como a cibercultura pode ser um elemento desencadeador de produção de tecnologias assistivas para os alunos surdos nas instituições de Ensino Superior.

Com o passar das décadas, houve uma evolução no que tange à inclusão de sujeitos surdos, já que estes estão presentes nas escolas, mercado de trabalho e em outros ambientes sociais. O movimento da inclusão é um processo amplo e complexo, permeado por inúmeras reflexões, discussões e com embates teóricos significativos, o que culminou em leis que intensificaram e contribuíram para o que atualmente entendemos por "sujeito surdo".

Pode-se classificar essa pesquisa, do ponto de vista de sua natureza, como pesquisa qualitativa, uma vez que tem como objetivo gerar conhecimentos novos e de interesse universal. Esta é de cunho bibliográfico e será elaborada mediante a leitura sistemática de livros, artigos e periódicos, com fichamento de cada obra, ressaltando os pontos abordados pelos autores.

A estrutura desta pesquisa apresenta, inicialmente, considerações sobre o conceito de tecnologia, sua evolução e tendências. Posteriormente, este estudo se dedicou a analisar as tecnologias assistivas, tendo como enfoque principal as tecnologias da informação e comunicação, que visam a auxiliar a comunicação entre ouvintes e surdos no Ensino Superior.

Observa-se que as tecnologias cada vez mais permeiam os lares, porém, ainda há muito que se fazer, principalmente nos aspectos educacionais e, principalmente, para a inclusão. O uso das TIC para a inclusão social, cultural e no contexto de acesso e apropriação tem alguns caminhos a percorrer, por exemplo, uma formação com mais habilidades por parte dos educadores, elaboração de conteúdos e plataformas com estilos aos quais os deficientes possam ter acesso e se apropriar dessas informações.

\section{Cibercultura e o sujeito surdo}

Ao abordar a temática sobre educação, surgem um conjunto de ideias e conceitos formais e informais com relação à mesma. A educação não se limita apenas a uma ciência com conceitos comprovados cientificamente. Abrange, também, o senso comum, valorizando o que há de experiências e vivências dos sujeitos que estão presentes na sociedade.

Quando a educação tem o objetivo de educar sujeitos, essa não se restringe apenas à transmissão de conteúdo, teorias ou informações comprovadas cientificamente. $\mathrm{O}$ modelo de 
educação que está sendo aqui tratado é aquele que auxilia os sujeitos a transformarem suas vidas em constantes processos de aprendizagem. O que tanto se almeja é que a educação contribua para uma melhor formação pessoal e profissional dos sujeitos, auxiliando os mesmos na formação de suas identidades. Nessa perspectiva, a educação contribui para a formação do sujeito, de modo que este consiga aprimorar suas habilidades de se comunicar, de compreender suas emoções e de se empoderar.

Moran (2012) provoca-nos a pensar que educar é contribuir para que os professores e alunos consigam transformar suas vidas em um processo constante de aprendizagem, seja dentro de escolas ou em outras organizações. Ao auxiliar os alunos nesse processo de aprendizagem, é importante também contribuir na construção de identidade dos mesmos, sendo necessário desenvolver as habilidades de comunicação, compreensão e emoção, as quais lhe permitam ter seu espaço pessoal, social e profissional na sociedade:

\begin{abstract}
$\mathrm{Na}$ sociedade do Século 21, em razão da revolução tecnológica e epistemológica ocorrida ao longo das últimas três décadas, ocorrem mudanças vertiginosas no conhecimento científico e nos produtos do pensamento, cultura e arte. Tão intensa é a produção do conhecimento e sua divulgação, que ensinar para produzir não mais atende as demandas postas pela sociedade informacional e global, em que estamos inseridos, a qual prioriza o domínio de certos saberes, habilidades e competências dos quais nós como educadores precisamos estar cientes e convencidos de sua necessidade (NOGARO; CERUTTI, 2016, p. 40).
\end{abstract}

Ao pensar em educar na sociedade atual, não se espera que o estudante seja um reprodutor das informações que obteve, mas que desenvolva suas capacidades para pesquisar, buscar informações, tornando-se um sujeito crítico que consiga opinar e intervir no seu meio. Torna-se oportuno, também, pensar que educar na contemporaneidade envolve a utilização de diferentes recursos facilitadores da aprendizagem, entre eles, os tecnológicos. Nota-se que as tecnologias estão presentes diariamente em diversos espaços, seja no ambiente de trabalho, escolas, ambientes comerciais ou domiciliares e seu uso é tão natural que muitas vezes acaba sendo uma atitude involuntária. As tecnologias foram incorporadas à vida, não sendo mais possível dissociá-las:

O ritmo com o qual as inovações tecnológicas vêm ganhando espaço na sociedade moderna provoca uma intensa necessidade do ser humano educarse para as mediações que se constroem entre os conteúdos que desenham as profissões e o ambiente vivido pelas organizações modernas. Novas habilidades, novos significados e constantes rupturas no campo dos valores éticos que conformam o mundo do trabalho desenham a estrutura que rege as organizações, particularmente aquelas que estão voltadas ao setor público 
estatal (BIZELLI; CUNHADARIDO, 2013, p. 513).

Conforme Lévy (1999), essa inserção das Tecnologias da Informação e Comunicação -TICs - na cultura e vida diária dos sujeitos é identificada pelo termo cibercultura, o qual está inserido no ciberespaço, conceito que o autor apresenta com a seguinte definição:

Eu defino o ciberespaço como o espaço de comunicação aberto pela interconexão mundial dos computadores e das memórias dos computadores. Essa definição inclui o conjunto dos sistemas de comunicação eletrônicos (aí incluídos os conjuntos de redes hertzianas e telefônicas clássicas), na medida em que transmitem informações provenientes de fontes digitais ou destinadas a digitalização. Insisto na codificação digital, pois ela condiciona o caráter plástico, fluido, calculável com precisão e tratável em tempo real, hipertextual, interativo e, resumindo, virtual da informação que é, pareceme, a marca distinta do ciberespaço (LÉVY, 1999, p. 93).

Nesse contexto, a cibercultura amplia a comunicação, rompendo as barreiras comunicacionais entre os sujeitos. Desse modo, possibilita experimentar, coletivamente, diferentes formas de comunicação, as quais vão além das que as mídias clássicas propõem.

Quando são agregadas tecnologias para auxiliar na comunicação, está se buscando aperfeiçoar a eficiência da atividade humana em todas as esferas, principalmente na produtiva. A tecnologia caracteriza-se pela transformação no campo tecnológico, portanto, consequentemente, no mercado de bens, serviços e consumo no modo de produção, na educação/qualificação e nas relações sociais.

Vivencia-se uma sociedade da informação, em que as pessoas necessitam de aprender a sair do individual e partir para o social, reaprendendo a integrar o humano como tecnológico, buscando, assim, as informações e maneiras diferenciadas de utilizá-las no seu cotidiano, seja para uso pessoal ou profissional.

Conforme Pinto (2004), quando são integradas as tecnologias temáticas, audiovisuais, orais, musicais, textuais, corporais e lúdicas, numa visão inovadora, é possível adquirir resultados positivos. Não basta apenas ter conhecimento da existência da tecnologia, é necessário buscar maneiras para compreender de que forma a tecnologia pode auxiliar e qual a função da mesma. Assim, quando utilizada, gerará resultados positivos, atendendo às necessidades iniciais.

Nesse sentido, ocorrem várias renovações nos meios tecnológicos em diferentes áreas e, consequentemente, a sociedade está em constantes transformações, assim, fazendo com que as pessoas inseridas nela busquem um aperfeiçoamento. O acesso às Tecnologias da Informação e Comunicação (TIC) desencadeia transformações sociais e diversas mudanças na 
forma de construir o conhecimento, sendo assim, a sociedade e os locais não podem desconsiderar esses movimentos.

Com base em Valente (2011), se o sujeito que está fazendo uso das tecnologias não compreender a função ou características dessa tecnologia, a mesma não será assimilável. Portanto, tais tecnologias estão sendo aprimoradas para se acomodar aos conhecimentos e necessidades de seus usuários, utilizando linguagens de interfaces sensoriais, sonoras e gestuais no seu desenvolvimento para facilitar essa apropriação digital.

Diante das mudanças provocadas pelo desenvolvimento tecnológico, é importante salientar que os usos desses recursos precisam acrescentar um significado aos usuários, que devem se apropriar criticamente dessas tecnologias, de modo a descobrir as possibilidades que as mesmas oferecem.

Adorno (2003, p.6) ressalta que:

Um mundo em que a técnica ocupa uma posição tão decisiva como acontece atualmente, gera pessoas tecnológicas, afinadas com a técnica. Isto tem a sua racionalidade boa: em seu plano mais restrito elas serão menos influenciáveis, com as correspondentes conseqüências no plano geral. Por outro lado, na relação atual com a técnica existe algo de exagerado, irracional, patogênico. Isto se vincula ao "véu tecnológico". Os homens inclinam-se a considerar a técnica como sendo algo em si mesma, um fim em si mesmo, uma força própria, esquecendo que ela é a extensão do braço dos homens. Os meios e a técnica é um conceito de meios dirigidos à autoconservação da espécie humana são fetichizados, porque os fins uma vida humana digna encontram-se encobertos e desconectados da consciência das pessoas.

Diante do exposto, fica evidente que as tecnologias não devem ser vistas como algo que substitua o ser humano, mas como algo que venha facilitar e complementar a capacidade da pessoa que a utiliza, aprimorando, nesse sentido, a atividade humana. Por isso, é importante que os sujeitos tenham consciência de que as tecnologias necessitam de um usuário para gerar uma ação.

\section{Tecnologias como facilitadoras na comunicação entre alunos ouvintes e surdos}

O termo tecnologia é atual, mas composto por dois radicais gregos: tecknos e logos. Dito de um modo mais explícito, "a tecnologia envolve um conjunto organizado e sistematizado de diferentes conhecimentos, científicos, empíricos e até intuitivos voltados para um processo de aplicação na produção e na comercialização de bens e serviços" 
(GRINSPUN, 1999, p. 49). A tecnologia é um suporte para o ser humano, ajudando o mesmo a realizar suas tarefas com maior facilidade.

Ao compreender as tecnologias como suporte para o ser humano, estas, quando aplicadas ou postas em movimento, podem auxiliar e minimizar as limitações dos sujeitos. As tecnologias, nesse sentido, representam possibilidades de auxílio para as pessoas com deficiência auditiva, especialmente por facilitar a comunicação não verbal com os sujeitos ouvintes e com o mundo:

A emergência de novas tecnologias possibilita e motiva alterações na dinâmica social, perpassando os mais diversos âmbitos, desde o cultural até o econômico. Além disso, o desenvolvimento e utilização de novas tecnologias modifica, de maneira profunda, a relação do ser humano com o conhecimento. Mesmo com as inúmeras mudanças observadas, as instituições de ensino tradicionais encontram dificuldades, e até resistência, em modificar sua estrutura em conformidade com os novos princípios sociais e tecnológicos. Ainda que TIC adentrem o espaço escolar nas áreas administrativas e de gestão, as mudanças ocorrem em menor dimensão nos âmbitos pedagógicos e metodológicos (MARTÍNEZ, BIZELLI, INFORSATO, p. 1436).

Nos últimos séculos, a sociedade vem sofrendo aceleradas mudanças. A tecnologia está presente diariamente na vida do ser humano e, através dela, surgem elementos para a produção de novos conhecimentos. Em meio a essas mudanças, a inclusão das pessoas com deficiência ganhou novas dimensões com o avanço de recursos físicos e tecnológicos:

[...] o ensino e aprendizagem têm suas estratégias e contam com políticas pedagógicas diferenciadas de acordo com a instituição, mas, por outro lado, a formação de professores no desenvolvimento das habilidades e competências ainda requer um olhar mais crítico quanto aos currículos dos cursos de graduação e licenciatura para formar educadores para atuar com a educação inclusiva, sendo assim, observar a formação desse sujeito e inserilo no mercado de trabalho, tanto no setor privado quanto público, ainda requer mais atenção. Nota-se que os professores e estudantes falam sobre a inclusão, mas de fato deve-se aprimorar as habilidades e competências da sociedade como um todo nessa questão (SARTORI et al., 2017, p. 879).

Pensando na inclusão dos surdos, é fundamental apostar na promoção da acessibilidade das pessoas com deficiências auditivas às tecnologias, por acreditar que estas apresentam recursos que facilitem a comunicação entre surdos e o mundo. Dito de outro modo, as tecnologias precisam ser vistas como parte de uma solução, e não o contrário.

Com o processo de inclusão e inserção das tecnologias, as pessoas com deficiência estão conquistando seu espaço e reconhecimento na sociedade. As mesmas já obtiveram 
diversos avanços, entre eles, foram elaborados leis e decretos que asseguram o direito de inclusão e igualdade nos diversos ambientes sociais.

Desse modo, é necessário que os ambientes sociais estejam adequados e aptos para atender pessoas com qualquer tipo de deficiência, ampliando, desse modo, as chances de que esse perfil da população tenha experiências satisfatórias a partir de suas vivências. Muitas vezes, é possível utilizar recursos ou tecnologias digitais que possam auxiliar nesse processo de inclusão, conforme orienta o Decreto Federal no 3.298, em seu Artigo 19 (BRASIL,1999):

Consideram-se ajudas técnicas, para os efeitos deste Decreto, os elementos que permitem compensar uma ou mais limitações funcionais motoras, sensoriais ou mentais da pessoa portadora de deficiência, como objetivo de permitir-lhe superar as barreiras da comunicação e da mobilidade e de possibilitar sua plena inclusão social.

Parágrafo único.

São ajudas técnicas:

I - próteses auditivas, visuais e físicas;

II - órteses que favoreçam a adequação funcional;

III - equipamentos e elementos necessários à terapia e reabilitação da pessoa portadora de deficiência;

IV - equipamentos, maquinarias e utensílios de trabalho especialmente desenhados ou adaptados para uso por pessoa portadora de deficiência;

$\mathrm{V}$ - elementos de mobilidade, cuidado e higiene pessoal necessários para facilitar a autonomia e a segurança da pessoa portadora de deficiência;

VI - elementos especiais para facilitar a comunicação, a informação e a sinalização para pessoa portadora de deficiência;

VII - equipamentos e material pedagógico especial para educação, capacitação e recreação da pessoa portadora de deficiência;

VIII - adaptações ambientais e outras que garantam o acesso, a melhoria funcional e a autonomia pessoal; e

IX - bolsas coletoras para os portadores de ostomia.

Essas ajudas técnicas também são conhecidas como tecnologias assistivas e devem colaborar para a inclusão social de pessoas com deficiências, sejam estas pessoas com deficiências visual, auditiva, física e/ou intelectual, reduzindo assim as limitações decorrentes das mesmas.

Nesse contexto, reconhece-se que o uso das TIC tornou-se um importante meio de inclusão e interação no mundo, sendo algo cada vez mais presente na cultura (LEVY, 1999). Podem-se citar as redes sociais ou os aplicativos para aparelhos celulares como exemplos de tecnologias que facilitam a interação e comunicação entre as pessoas, independentemente de estarem próximas ou distantes. Essa afirmação é ainda mais evidente quando nos referimos ao uso das TIC por pessoas com deficiência:

Desta forma, articular o uso pedagógico das tecnologias digitais por meio do PPP favorece o acesso e a permanência do educando na escola, 
potencializando o desenvolvimento das novas práticas, qualifica os profissionais, favorece o desenvolvimento da autonomia do aluno, novas concepções de aprendizagem, proporciona melhores oportunidades e estimula a colaboração entre alunos e docentes (VOSGERAU; ROSSARI, 2017, p. 1035).

As tecnologias assistivas e as TICs podem ser utilizadas de diferentes maneiras, podendo sua utilização ser classificada de diversas formas, de acordo com os objetivos do pesquisador. Conforme Santarosa (1997), as TICs podem ser classificadas em quatro áreas, a saber: sistemas auxiliares ou prótese para a comunicação; as utilizadas para controle do ambiente; as TICs como ferramentas ou ambientes de aprendizagem e as TICs como meio de inserção no mundo do trabalho profissional. Optou-se, neste artigo, por descrever as que são classificadas como facilitadoras da comunicação e também da aprendizagem do sujeito surdo, sendo entendidas como:

\begin{abstract}
As TIC como sistemas auxiliares ou prótese para a comunicação: talvez esta seja a área onde as TIC tenham possibilitado avanços mais significativos. Em muitos casos o uso dessas tecnologias tem se constituído na única maneira pela qual diversas pessoas podem comunicar-se com o mundo exterior, podendo explicitar seus desejos e pensamentos. Essas tecnologias tem possibilitado a otimização na utilização de Sistemas Alternativos e Aumentativos de Comunicação (SAAC), com a informatização dos métodos tradicionais de comunicação alternativa, como os sistemas Bliss, PCS ou PIC, entre outros. [...]

As TIC como ferramentas ou ambientes de aprendizagem: as dificuldades de muitas pessoas com necessidades educacionais especiais no seu processo de desenvolvimento e aprendizagem têm encontrado uma ajuda eficaz na utilização das TIC como ferramenta ou ambiente de aprendizagem.[...] (SANTAROSA, 1997, p. 115-138)
\end{abstract}

Utilizando as TIC com o intuito da comunicação, é possível romper com algumas barreiras comunicacionais. Indiferentemente de os sujeitos possuírem ou não limitações relacionadas à comunicação, através do uso dessa tecnologia, é possível estabelecer contato com outros sujeitos, estando esses próximos ou não, podendo também haver uma comunicação entre sujeitos que utilizam diferentes maneiras para se comunicar.

Partindo dessa ideia, veem ao encontro as tecnologias da informação e comunicação como ambientes de aprendizagem, as quais, quando utilizadas juntas, podem auxiliar na aprendizagem do sujeito surdo, auxiliando o mesmo a conseguir estabelecer comunicação com outros sujeitos e facilitando a sua aprendizagem através de recursos digitais.

As TIC podem ser classificadas de maneiras diferenciadas, sendo que cada uma tem por objetivo saciar ou aprimorar algo. Estas servem de suporte principalmente para as pessoas 
com alguma limitação ou deficiência, em diferentes atividades, seja das mais simples, até as mais complexas.

Atualmente, é possível ter contato com diferentes tecnologias, as quais, na maioria das vezes, são de fácil acesso para a população. No entanto, para que as tecnologias possam auxiliar no processo de inclusão, é necessário o interesse das pessoas em buscar o aperfeiçoamento para aprender a manusear tais recursos.

Os usuários precisam ter autodisciplina, criatividade, capacidade de trabalhar em grupo, ser adaptáveis e flexíveis, precisam constantemente buscar novas informações para aprimorar o conhecimento, saber tomar decisões, ser críticos e não se deixar acomodar. Assim, é possível ressaltar a importância de as pessoas estarem em constantes atualizações. Betts (2005, p. 28-29) acrescenta que:

\begin{abstract}
Além de transformar-se num aprendiz vitalício e ser responsável pela própria carreira, o trabalhador, para ter sucesso na era do conhecimento, terá de desenvolver outras competências. Para citar apenas três, a primeira é aprender a aprender, gostar de aprender, ter curiosidade, capacidade de coletar, organizar, estruturar, analisar e qualificar a informação e construir conhecimento - ser autodidata.

A segunda é uma certa inconformidade com o estado presente, uma disposição para o novo, para mudar constantemente, enfim, altamente adaptável. A terceira é a autodisciplina, ou seja, a clareza de objetivos, gestão do tempo, sem as quais terá uma "indigestão" informacional dado o volume de informações espalhadas e acessíveis mundo afora.
\end{abstract}

Pensando no fácil acesso às mídias digitais e nos avanços tecnológicos, é fundamental a inclusão destes nos ambientes onde ocorre a difusão do conhecimento ou onde surge a necessidade de saciar algo, mesmo que em alguns locais essas ferramentas estejam em fase de avaliação ou sejam vistas como polêmicas devido à sua utilização (PERNISA e VIANA, 2010).

As TICs beneficiam em geral todos os públicos. No entanto, é notável que elas desempenham um papel fundamental com deficientes, uma vez que os permitem desenvolver atividades que antes estavam inacessíveis devido às limitações da pessoa com deficiência.

Diferentes tecnologias surgem ao longo do tempo, entre elas, as que visam a facilitar as relações entre os sujeitos. Ao pensar nas tecnologias voltadas para a independência dos seres humanos, é possível mencionar as tecnologias assistivas, utilizadas com o objetivo de mediação, ferramenta e instrumento que facilitem as atividades que envolvam a autonomia, principalmente das pessoas com deficiências (GALVÃO FILHO, 2009).

Lauand (2005) explica que: 
No sentido amplo, o objeto da tecnologia assistiva é uma ampla variedade de recursos destinados a dar suporte (mecânico, elétrico, eletrônico, computadorizado, etc.) à pessoas com deficiência física, visual, auditiva, mental ou múltipla. Esses suportes podem ser, por exemplo, uma cadeira de rodas [...], uma prótese, uma órtese, e uma série infindável de adaptações, aparelhos e equipamentos nas mais diversas áreas de necessidade pessoal (comunicação, alimentação, transporte, educação, lazer, esporte, trabalho, elementos arquitetônicos e outras) (LAUAND, 2005, p. 30).

É possível compreender as tecnologias assistivas como recursos que permitem a ampliação das habilidades ou como suporte das limitações de cada sujeito com deficiência, podendo essas serem adaptadas para diferentes áreas e utilizadas com diferentes objetivos. Tais tecnologias não se limitam apenas a uma deficiência, podendo ser executadas com diferentes objetivos, conforme a necessidade de cada sujeito.

Cada tecnologia possui a sua função, podendo o sujeito optar por qual melhor se adapta as suas necessidades. Assim, essas tecnologias auxiliam as pessoas em diversas atividades, desde as tarefas simples do seu cotidiano até as mais complexas, nas quais surgem maiores limitações conforme a deficiência.

Em um mundo com aceleradas e constantes mudanças, as tecnologias assistivas ocupam uma área do conhecimento e de pesquisa de grande relevância onde, através destas, surgem novos horizontes de possibilidades para a real inclusão social de pessoas com deficiência (GALVÃO FILHO, 2009).

Essas tecnologias podem fazer com que as pessoas com deficiência tenham mais autonomia, facilitando a comunicação com outras pessoas, ajudando em aspectos psicomotores e auxiliando em inúmeras tarefas, sendo recursos para ultrapassar barreiras físicas e socioeconômicas.

Assim, as tecnologias podem ser facilitadoras em vários aspectos e representam, para as pessoas com deficiência, um complemento para suas habilidades, minimizando suas limitações. Elas podem ser vistas como recursos que proporcionam melhorias qualitativas e quantitativas das estratégias para realizar uma determinada atividade, além de aprimoramento das capacidades físicas e intelectuais dos sujeitos.

Ao ingressar no Ensino Superior, o sujeito surdo torna-se minoria perante os sujeitos ouvintes e o que prevalece são as características próprias da comunidade ouvinte. Assim, a língua majoritária é o português oral/auditivo.

Sabe-se que, devido às limitações auditivas, o sujeito surdo muitas vezes acaba se privando de informações e contato no cotidiano, da mesma maneira que um público com 
desconhecimento da língua de sinais acaba gerando uma privação aos sujeitos surdos quanto às suas necessidades.

A Língua Brasileira de Sinais (LIBRAS) é o alicerce da compreensão e comunicação dos surdos, portanto, quando os sujeitos ouvintes possuem conhecimento com relação à mesma, conseguem estabelecer uma comunicação ideal com os sujeitos surdos.

Conforme a Lei $\mathrm{n}^{\mathrm{o}} 12.319$, de primeiro de setembro de 2010, é regulamentada a profissão de Tradutor e Intérprete da Língua Brasileira de Sinais - LIBRAS. Este profissional é habilitado para realizar traduções entre Libras-Português ou vice-versa, sendo primordial a sua presença na instituição de ensino superior (IES) para que o sujeito surdo não seja privado das informações ou excluído em seu grupo acadêmico.

No entanto, somente a presença do intérprete no ambiente onde o sujeito surdo está inserido não é garantia de uma plena inclusão, afinal, segundo Stumpf (2008, p. 27):

[...] a inclusão acontece a partir de dois movimentos: da construção social de toda a sociedade que entende e acolhe, e dos surdos, que vão participar porque se sentem acolhidos [...] Este movimento da sociedade implica em responsabilidade social como prática constante no agir das pessoas e das instituições a partir de uma posição ética, uma posição em que a liberdade individual é posta em segundo plano a fim de que a justiça assuma primazia nas relações intersubjetivas.

Percebe-se que a inclusão do sujeito surdo se torna mais viável quando há planejamento, quando os assuntos são pensados considerando a preservação da identidade surda e partindo das características próprias da mesma para, assim, elaborar alternativas que visem à inclusão desses sujeitos.

Ao pensar no ensino superior, é necessário encontrar estratégias que rompam as barreiras de comunicação entre surdos e ouvintes, sendo que as TICs encontram-se como alternativa para minimizar tais barreiras. Pensando a partir de Nogaro e Cerutti (2016), é notável que os dispositivos comunicacionais atuais oportunizam possibilidades de interações entre as pessoas, sendo que as técnicas disponíveis revolucionaram a maneira de interação e comunicação entre os acadêmicos presentes nas universidades. Os autores ainda citam que:

As novas tecnologias estão cada vez mais presentes, abrindo amplas oportunidades de produção individual e coletiva, gerando a construção de conhecimentos a partir das interações com o meio, pois a aprendizagem vai sendo construída pelas interações, cooperações, acessos e trocas de informações que sempre fizeram parte das vivências da sociedade, mas que nem sempre foram partilhadas pela ausência de ferramental adequado (NOGARO; CERUTTI, 2016, p. 94). 
Através das tecnologias, é possível aproximar os sujeitos surdos e ouvintes, pois, por meio dessas, surgem oportunidades de comunicação entre ambos, uma vez que é possível estabelecer comunicação por meio de diferentes tecnologias através da língua portuguesa escrita, da qual surdos e ouvintes possuem domínio. É preciso criar uma cultura de colaboração, envolvendo professores comuns, professores especializados, gestão da escola, família, parceiros da comunidade, enfim, todos os recursos humanos capazes de oferecer à escola e aos alunos condições plenas de desenvolvimento (CARNEIRO; UEHARA, 2016).

Constatou-se, através deste artigo, que, quando há uma relação com produções coletivas, os sujeitos estabelecem vínculos e interações. Assim, as tecnologias são fundamentais para que, por meio delas, os sujeitos consigam de maneira mais acessível trocar informações e ideias, o que acarretará em sujeitos mais reflexivos e com diferentes opiniões sobre um mesmo assunto.

\section{Considerações finais}

Ao longo deste artigo, foi possível perceber que houve avanços nas tecnologias de um modo geral e que, atualmente, não é mais possível excluí-las do cotidiano. As tecnologias assistivas e as TIC estão inseridas e são utilizadas pelos usuários diariamente, seja para a realização de atividades mais simples e corriqueiras, seja para a realização das mais complexas, tais como locomover-se, estabelecer comunicação com outros sujeitos, melhorar a visão, entre outras.

Ao pensar na inclusão do sujeito surdo no Ensino Superior, é importante considerar que a presença do intérprete não é suficiente, tornando necessário que a equipe de profissionais busque de maneira coletiva alternativas e metodologias apropriadas também para os estudantes surdos. É fundamental um conjunto de ações para que o aluno surdo se sinta integrado ao espaço educacional, criando vínculos afetivos, profissionais e pessoais com o restante da comunidade escolar.

Verificou-se que uma das alternativas pode ser a utilização das tecnologias assistivas durante as aulas, devido ao fato de as mesmas auxiliariam nas limitações dos sujeitos surdos. Assim, facilitando e possibilitando uma comunicação entre sujeitos surdos e ouvintes não somente nas instituições de ensino superior, mas também em outros ambientes e situações.

Compreende-se que as tecnologias assistivas são utilizadas para diferentes fins, mas, ao pensar-se nos estudantes surdos de Ensino Superior, utilizam-se, principalmente, as mesmas com o objetivo de facilitar e possibilitar a comunicação entre os sujeitos ali presentes. 
Sabe-se que, quando há comunicação, principalmente em um espaço de ensino, é possível facilitar e proporcionar uma aprendizagem mais ampla e diversificada. Portanto, é possível afirmar que as tecnologias assistivas também são ferramentas importantes e fundamentais para o processo de aprendizagem dos sujeitos.

Percebe-se que a falta de domínio de uma língua acaba privando o sujeito de muitos fatores do cotidiano, da mesma maneira que um profissional com desconhecimento da língua de sinais acaba gerando uma privação dos sujeitos surdos quanto às suas necessidades. A LIBRAS é o alicerce da compreensão e comunicação dos surdos, portanto, quando os ambientes e os profissionais estão habilitados quanto à mesma, contribuem para uma inclusão com qualidade destes sujeitos.

Conclui-se que, por meio das tecnologias assistivas, entre elas as TICs, é possível facilitar esse processo de inclusão dos surdos nas instituições de ensino superior. Assim, rompendo as barreiras da comunicação entre surdos-ouvintes e transformando esses ambientes em algo verdadeiramente democrático.

\section{REFERÊNCIAS}

ADORNO, T. Educação após Auschwitz. 2003. Disponível em:

https://rizomas.net/arquivos/Adorno-Educacao-apos-Auschwitz.pdf. Acesso em: 15 jul. 2017.

BETTS, D. N. Desafios para o docente do século XXI: o impacto das novas tecnologias de informação e comunicação. In: DANYLUK, O. S.; QUEVEDO, H. F. de.; MATTOS, M. B. P. de (Org.). Passo Fundo: UPF, 2005.

BIZELLI, J. L.; CUNHA DARIDO, M. O processo de construção da Unesp corporativa. Revista Ibero-Americana de Estudos em Educação, Araraquara, v.8, n.2, 2013.

BRASIL. Decreto Federal n⿳3.298, Regulamenta a Lei $n^{\mathbf{0}}$ 7.853, de 24 de outubro de 1989, dispõe sobre a Política Nacional para a Integração da Pessoa Portadora de Deficiência, consolida as normas de proteção, e dá outras providências. Brasília, 20 de dezembro de 1999.

CARNEIRO, R. U. C.; UEHARA, F. A inclusão de alunos público-alvo da educação especial no ensino fundamental I através do olhar dos professores. Revista Ibero-Americana de Estudos em Educação, Araraquara, v. 11, n. esp. 2, p.911-934, 2016. DOI: 10.21723/riaee. v11. esp2. p911-934.

GALVÃO FILHO, T. A. Tecnologia Assistiva para uma Escola Inclusiva: Apropriação, Demandas e Perspectivas. 2009. 346 f. Dissertação (Doutorado em Educação) - Faculdade de Educação, UFBA, Salvador, 2009.

GRINSPUN, M. P. S. Z. Educação Tecnológica. In: GRINSPUN, Mírian Paura Sabrosa Zippin (Org.) Educação Tecnológica: desafios e perspectivas. São Paulo, Ed. Cortez, 1999.

RPGE- Revista on line de Política e Gestão Educacional, Araraquara, v. 22, n. 3, p. 1065-1080, set./dez., 2018. E-ISSN:1519-9029. DOI: $10.22633 /$ rpge.v22i3.11874 
LAUAND, G. B. A. Fontes de informação sobre tecnologia assistiva para favorecer à inclusão escolar de alunos com deficiências físicas e múltiplas. Tese (Doutorado em Educação Especial) Programa de Pós-graduação em Educação Especial, Universidade Federal de São Carlos. São Carlos, 2005.

LÉVY, P. Cibercultura. São Paulo: Editora 34, 1999.

MARTÍNEZ, D. É. G.; BIZELLI, J. L.; INFORSATO, E. do C. Tecnologias de informação e comunicação no ensino superior: o ambiente virtual de aprendizagem em curso semipresencial. Revista Ibero-Americana de Estudos em Educação, Araraquara, v. 12, n. esp. 2, p. 1349-1371, ago./2017. E-ISSN: 1982-5587. DOI: 10.21723/riaee.v12.n.esp.2.10302.

MCT - Ministério de Ciência e Tecnologia, 2005. Disponível em:

http://portal.mec.gov.br/seeep/index.phpoption=content\&task=view\&id=64Itemid=193. Acesso em: 06 jun. 2017.

MORAN, J. M. Novas tecnologias e mediação pedagógica. Campinas: ed. Papirus, 2012.

NOGARO, A.; CERUTTI, E. As tics nos labirintos da prática educativa. Curitiba: CRV, 2016.

NONATO, E. R. S. Novas tecnologias, educação e contemporaneidade. Rev. Práxis educativa, Ponta Grossa: PR, v. 1, n. 1, p. 77-86, jan./jun., 2006.

PERNISA JUNIOR, C.; VIANA, F. Interfaces do Saber: o uso das tecnologias digitais na difusão do conhecimento. Impulso, Piracicaba , v.20, n. 49, jan./jun., 2010.

PINTO, A. M. As novas Tecnologias e a educação. 2004. Disponível em: http://www.portalanpedsul.com.br/admin/uploads/2004/Poster/Poster/04_53_48_AS_NOVAS _TECNOLOGIAS_E_A_EDUCACAO.pdf. Acesso em: 08 jun. 2017.

SANTAROSA, L. M. C. "Escola virtual” para a educação especial: ambientes de aprendizagem telemáticos cooperativos como alternativa de desenvolvimento. Revista de Informática Educativa, Bogotá, v. 10, n. 1, p. 115-138, 1997.

SARTORI, D. V. B.; BERMEJO, L. J.; TANAKA, E. Z.; SANTOS CRUZ, J. A. C.; CAPETTI, L.; FERREIRA, L. R. Estudo analítico de publicações sobre EaD na educação especial como ferramenta pedagógica. Revista Ibero-Americana de Estudos em Educação, Araraquara, v. 12, n. 2, p. 862-883, 2017. E-ISSN: 1982-5587. DOI: 10.21723/riaee. v 12. n 2. 9825.

STUMPF, M. R. Mudanças estruturais para uma inclusão ética. In: QUADROS, Ronice. Estudos Surdos III. Petrópolis, RJ: Arara Azul, 2008. p.14-29.

VALENTE, J. A. As tecnologias e a verdadeira inovação. Pátio. Ano XIV - No 56 - Como as tecnologias transformam (ou não) a educação - Novembro 2010 / Janeiro 2011.

VOSGERAU, D. Sant'Anna R.; ROSSARI, M. Princípios orientadores da integração das tecnologias digitais ao projeto político-pedagógico. Revista Ibero-Americana de Estudos 
em Educação, Araraquara, v. 12, n. 2, p. 1020-1036, 2017. E-ISSN:1982-5587. DOI: 10.21723/riaee.v12.n2.9051.

\section{Como citar este artigo:}

TOSO, Carine.; CERUTTI, Elisabete.; GRANDI, Suzete.; SANTOS CRUZ, José Anderson. A tecnologia assistiva no ensino superior: reflexões sobre seu uso para alunos ouvintes e surdos. Revista on line de Política e Gestão Educacional, Araraquara, v. 22, n. 3, p. 10651080, set./dez., 2018. E-ISSN:1519-9029. DOI: 10.22633/rpge.v22i3.11874

Submetido em: $10 / 03 / 2018$

Aprovado em: 30/09/2018 